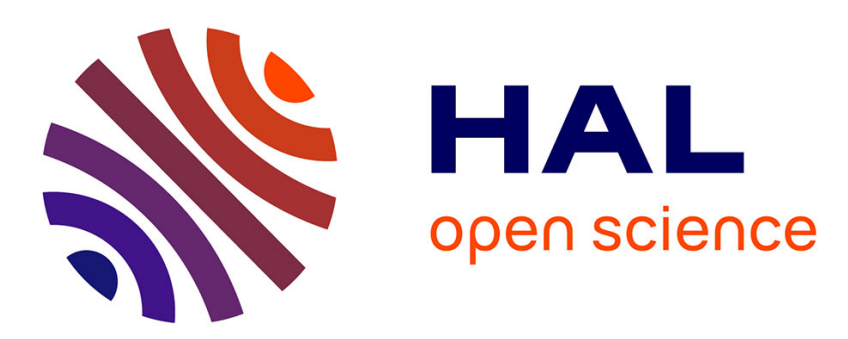

\title{
Steady-State and Transient Performance of Axial-Field Eddy-Current Coupling
}

Thierry Lubin, Abderrezak Rezzoug

\section{To cite this version:}

Thierry Lubin, Abderrezak Rezzoug. Steady-State and Transient Performance of Axial-Field EddyCurrent Coupling. IEEE Transactions on Industrial Electronics, 2015, 62 (4), pp.2287-2296. 10.1109/TIE.2014.2351785 . hal-01062497

\section{HAL Id: hal-01062497 https://hal.science/hal-01062497}

Submitted on 9 Sep 2014

HAL is a multi-disciplinary open access archive for the deposit and dissemination of scientific research documents, whether they are published or not. The documents may come from teaching and research institutions in France or abroad, or from public or private research centers.
L'archive ouverte pluridisciplinaire HAL, est destinée au dépôt et à la diffusion de documents scientifiques de niveau recherche, publiés ou non, émanant des établissements d'enseignement et de recherche français ou étrangers, des laboratoires publics ou privés. 


\title{
Steady-State and Transient Performance of Axial-Field Eddy-Current Coupling
}

\author{
Thierry Lubin, and Abderrezak Rezzoug \\ Université de Lorraine, Groupe de Recherche en Electrotechnique et Electronique de Nancy, GREEN, F-54500 \\ Vandœuvre-lès-Nancy, France
}

\begin{abstract}
This paper presents an approach for quick calculation of steady-state and transient performances of an axial-field eddy-current coupling. Based on a two-dimensional (2D) approximation of the magnetic field distribution, a simple analytical expression for the transmitted torque is first developed. This expression is valid for low slip values which correspond to the normal working area of such devices (high efficiency). The proposed torque formula is then used to study the steady-state (constant speed operations) and the transient performances of the coupling (small variations of the slip speed). The results are compared with those obtained from 3-D finite elements simulations and tests. It is shown that good agreements are obtained.
\end{abstract}

Index Terms-- Analytical model, magnetic transmission, eddy-current, torque, transient performance.

\section{NOMENCLATURE}

$R_{1} \quad$ Inner radius of the magnets

$R_{2} \quad$ Outer radius of the magnets

$R_{m} \quad$ Mean radius of the magnets $\left(R_{m}=\left(R_{1}+R_{2}\right) / 2\right)$

$R_{0} \quad$ Inner radius of the copper

$R_{3} \quad$ Outer radius of the copper

$L \quad$ Radial length of the magnets $\left(L=R_{2}-R_{l}\right)$

$H \quad$ Radial length of the copper $\left(H=R_{3}-R_{0}\right)$

$\lambda \quad$ Copper end-lengths to magnets length $\lambda=(H-L) / L$

$a$ Thickness of the back-iron (magnets side)

$b \quad$ Magnets thickness

$c \quad$ Air-gap thickness

$d \quad$ Copper thickness

$e \quad$ Thickness of the back-iron (copper side)

$\alpha \quad$ PMs pole-arc to pole-pitch ratio

$p \quad$ Pole-pairs number

$B_{r} \quad$ Remanence of the permanent magnets

$\sigma \quad$ Conductivity of the conducting plate (copper)

$\beta \quad \beta=p / R_{m}$

\section{INTRODUCTION}

$\mathrm{M}$ AGNETIC couplings can transmit a torque from a primary driver to a follower without mechanical contact. Therefore, they are well suited for use in isolated systems such as vacuums, high-pressure or cryogenic vessels. Compared to mechanical couplings, they present great advantages such as self protection against overload condition and great tolerance to shaft misalignment [1]-[4].

There are two main types of magnetic coupling: synchronous [1]-[13] and induction type (eddy-current) [14]-[30], both with radial or axial flux configuration. In this paper, we focus on single-sided axial field eddy-current coupling as shown in Fig. 1. It consists of two disks: one is composed of rare earth permanent magnets (axially magnetized), and the other one is equipped with a conducting plate (generally copper). To improve the performances, the flux is closed by two back iron yokes.

The working principle of eddy-current couplings is well known [14]. The eddy currents, which are induced in the conducting plate by the slip speed $\left(\Omega=\Omega_{1}-\Omega_{2}\right)$, interact with the magnetic field and generate a torque. The normal working range area of such devices corresponds to low slip values where the temperature rise, due to induced-current, is limited. In this condition, the torque is proportional to the slip [21]. As shown in [14], the efficiency of eddy-current couplings is given by $\eta=1-s$ where $s$ is the slip $\left(s=\Omega / \Omega_{1}\right)$.

Fig. 2 shows the prototype of the studied eddy-current coupling placed on the test bench. The physical and geometrical parameters are given in Table I. These parameters have been optimized but the optimization procedure is not developed in this paper. Design optimization of eddy-current couplings can be found in [22], [29] and [30]. With these parameters and considering $c=3 \mathrm{~mm}$ for the air-gap, we obtain a torque of about 10 $\mathrm{Nm}$ for a slip speed of $150 \mathrm{rpm}$ (11). A slip speed of 150 rpm corresponds to an efficiency of $95 \%(\eta=1-s)$ when the eddy-current coupling is used with a motor running at a nominal speed of $3000 \mathrm{rpm}$ [14].
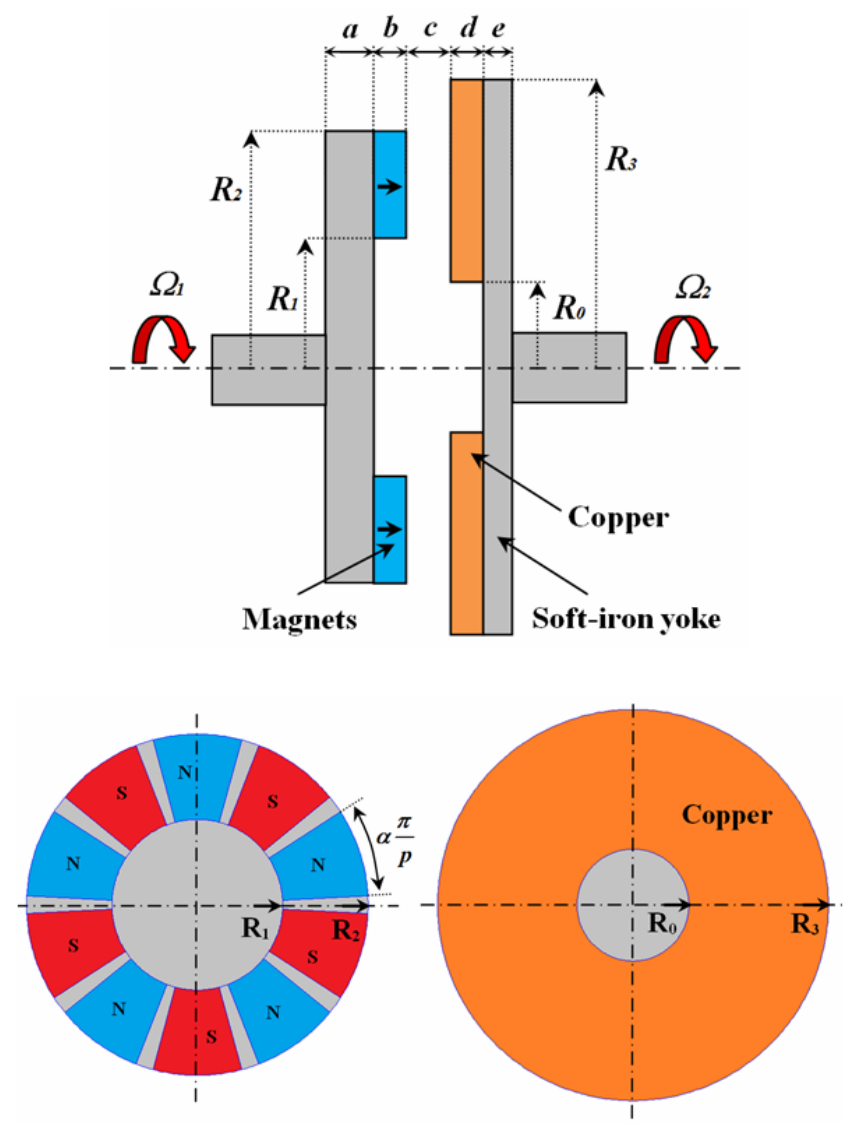

Fig. 1. Geometry of the studied axial-field eddy-current coupling $(p=5)$ with its geometrical parameters. 


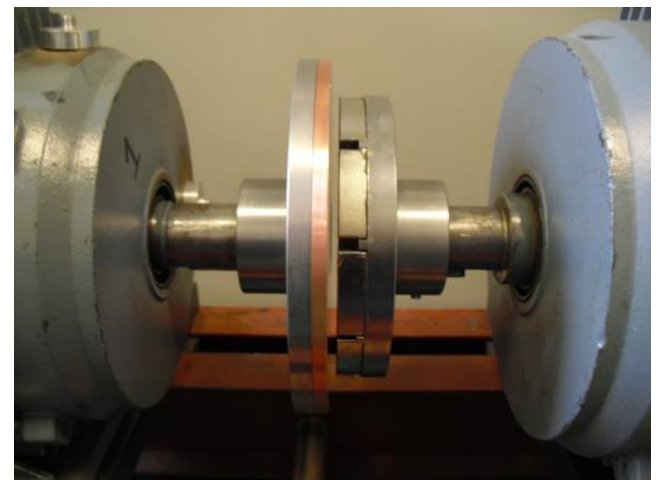

Fig. 2. Eddy-current coupling prototype (air-gap $c=3 \mathrm{~mm}$ ).

TABLE I

PARAMETERS OF THE STUDIED EDDY-CURRENT COUPLING

\begin{tabular}{lll}
\hline \hline \multirow{2}{*}{ Symbol } & \multicolumn{1}{c}{ Quantity } & \multicolumn{1}{c}{ value } \\
\hline$R_{1}$ & Inner radius of the magnets & $30 \mathrm{~mm}$ \\
$R_{2}$ & Outer radius of the magnets & $60 \mathrm{~mm}$ \\
$R_{0}$ & Inner radius of the conducting plate & $15 \mathrm{~mm}$ \\
$R_{3}$ & Outer radius of the conducting plate & $75 \mathrm{~mm}$ \\
$a$ & Thickness of the back-iron (magnets side) & $10 \mathrm{~mm}$ \\
$b$ & Magnets thickness & $10 \mathrm{~mm}$ \\
$c$ & Air-gap length & variable \\
$d$ & Conducting plate thickness & $5 \mathrm{~mm}$ \\
$e$ & Thickness of the back-iron (copper side) & $8 \mathrm{~mm}$ \\
$\alpha$ & PMs pole-arc to pole-pitch ratio & 0.9 \\
$p$ & Pole-pairs number & 5 \\
$B_{r}$ & Remanence of the permanent magnets (NdFeB) & $1.25 \mathrm{~T}$ \\
$\sigma$ & Conductivity of the conducting plate (copper) & $57 \mathrm{MS} / \mathrm{m}$ \\
\hline
\end{tabular}

Eddy-current couplings have been studied for a long time and many papers can be found in the literature [14]-[23] The study of such devices is usually based on a twodimensional approximation for the magnetic field distribution. The induced currents in the conducting plate are computed by solving a $2 \mathrm{D}$ diffusion equation leading to a complex expression for the transmitted torque [16]-[18]. More recently [20], [21], the magnetic equivalent circuit (MEC) method has been used to predict the performance of eddy-current couplings by taking into account the magnetic saturation effects and all material properties. With the MEC method, it is possible to study eddy-current couplings with complex geometries [23]. In such cases, analytical models have significant issues. The main drawback of the MEC method is that the flux paths must be a priori known in order to define the reluctance expressions which appear in the torque expression [20], [21], and [23].

For an engineering purpose, it is important to have a simple and accurate torque formula in order to quickly study the effects of geometrical parameters on the coupling performances. As indicated previously, the working area of eddy-current couplings corresponds to low slip values. Therefore, analysis of such device can be limited to low slip values, which simplify greatly the analytical development.

The goal of this paper is to develop the simplest model which gives acceptable results in the design area (low slips). To achieve this outcome, we have to do some assumptions that will be justified in the next developments. The 3D effects (actual paths of the induced currents) are taken into account by using the Russell correction factor [31]. The proposed torque formula, which depends directly on the physical and geometrical parameters, is then used for the analysis of both steady-state and transient operations. It should be noted that transient performance analysis of eddy- current couplings is rarely treated in the literature [24]-[26], and very few experimental results are given [27], [28].

\section{TORQUE EXPRESSION FOR LOW SLIP VALUES}

Axial flux eddy-current coupling is an inherent 3D geometry from the modeling point of view. However, in order to simplify the analysis, the 3D problem of Fig. 1 can be reduced to a $2 \mathrm{D}$ problem by introducing a cutting plane at the average radius of the magnets $R_{m}=\left(R_{1}+R_{2}\right) / 2$. Fig. 3 shows the resulting 2D model in Cartesian coordinate $(y, z)$ with an infinite length along the $x$-direction. The $3 \mathrm{D}$ effects (actual path of the induced currents) cannot be overlooked for such device and will be taken into account by using the classical Russell correction factor [31]. Moreover, for reasons of simplicity, we adopt the following assumptions:

1) The reaction field due to induced currents is neglected because of the low slips assumption,

2) The iron-yokes are considered with infinite magnetic permeability and zero conductivity,

3) Only the first harmonic is considered for the magnetic field distribution,

4) Magnets are axially magnetized with relative recoil permeability $\mu_{r}=1$.

As the iron-yokes present an infinite permeability, the tangential component of the magnetic field is zero at $z=0$ and $z=b+c+d$ (boundary conditions). This limits the number of region where the magnetic field has to be computed. This hypothesis can be regarded as accurate because the thicknesses $a$ and $e$ of the back-iron (see Fig. 3) must be determined to avoid magnetic saturation.

As it can be seen in Fig. 3, the whole domain of the field problem is divided into two regions: the PMs region (region I) and the air-gap with copper region (region II). As the reaction field is neglected, the air-gap and copper can be connected because we have the same governing equation for this region, i.e. Laplace's equation.

A magnetic vector potential formulation $\left(A_{i}=A_{i}(y, z) \mathbf{e}_{\mathbf{x}}\right)$ is used to solve the problem. From the Maxwell equations and considering the adopted assumptions, we have to solve the following equations in each region

$$
\begin{aligned}
& \frac{\partial^{2} A_{I}}{\partial y^{2}}+\frac{\partial^{2} A_{I}}{\partial z^{2}}=-\mu_{0} \frac{\partial M_{z}}{\partial y} \quad \text { in Regions I (PMs) } \\
& \frac{\partial^{2} A_{I I}}{\partial y^{2}}+\frac{\partial^{2} A_{I I}}{\partial z^{2}}=0 \quad \text { in Region II (air - gap and copper) }
\end{aligned}
$$

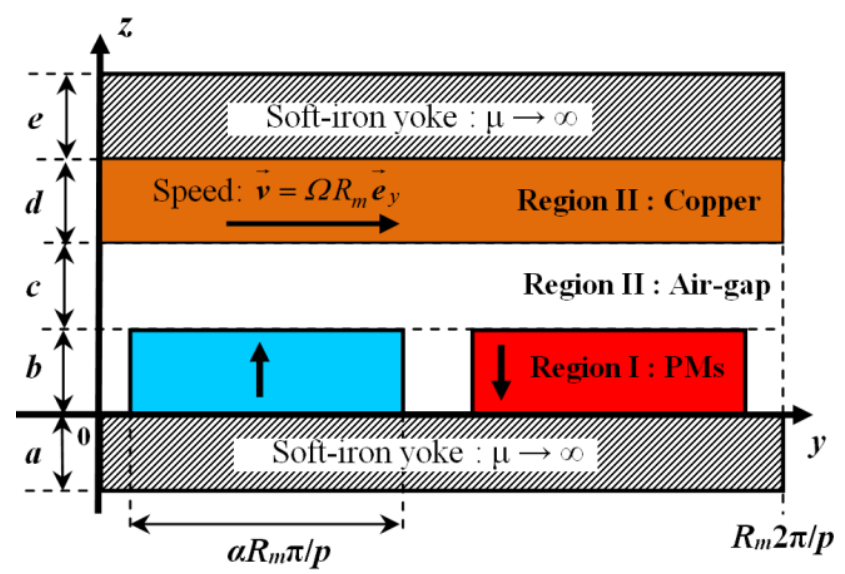

Fig. 3. 2D model of the eddy-current coupling at the mean radius of the magnets $R_{m}=\left(R_{1}+R_{2}\right) / 2$. 
where $\mu_{0}$ is the vacuum permeability and $M_{z}$ is the axial magnetization of the magnets. The distribution of the axial magnetization $M_{z}(y)$ is plotted in Fig. 4. The axial magnetization can be expressed in Fourier's series. It has been shown in [18] that the first harmonic component plays a dominant role in the torque transmission for eddy-current couplings (around $98 \%$ of the total torque). So, in the following development, we will consider only the first harmonic of the magnetization.

$$
M_{z}(y)=\frac{4 B_{r}}{\pi \mu_{0}} \sin \left(\alpha \frac{\pi}{2}\right) \sin (\beta y) \quad \text { with } \quad \beta=p / R_{m}
$$

According to the symmetry of the magnetic field distribution and considering the classical boundary and interface conditions for such problem, solutions of (1) is

$$
\begin{aligned}
& A_{I}(y, z)=K\left(1-\frac{\sinh (\beta(c+d)) \cosh (\beta z)}{\sinh (\beta(b+c+d))}\right) \cos (\beta y) \\
& A_{I I}(y, z)=K \frac{\sinh (\beta b) \cosh (\beta(z-(b+c+d)))}{\sinh (\beta(b+c+d))} \cos (\beta y)
\end{aligned}
$$

with

$$
K=\frac{4 B_{r} R_{m}}{\pi p} \sin (\alpha \pi / 2)
$$

The induced current density in the conducting plate can be deduced from Lorentz's equation

$$
\boldsymbol{J}=\sigma \boldsymbol{v} \times \boldsymbol{B}_{I I}=-\sigma \Omega R_{m} \frac{\partial A_{I I}}{\partial y} \boldsymbol{e}_{\boldsymbol{x}}
$$

where $\Omega=\Omega_{1}-\Omega_{2}$ is the slip speed ( $r d / s$ ) between the two discs. The transmitted torque can be evaluate by the power losses dissipated in the conducting plate

$$
T=\frac{P}{\Omega}=\frac{L}{\sigma \Omega} \int_{0}^{2 \pi R_{m}} \int_{b+c}^{b+c+d} J^{2}(y, z) d y d z
$$

From (4), (6) and (7), we can derive a closed-form expression for the electromagnetic torque which depends directly on the physical and geometrical parameters

$$
T=K_{T} \Omega=K_{T}\left(\Omega_{1}-\Omega_{2}\right)
$$

where $K_{T}$ is given by

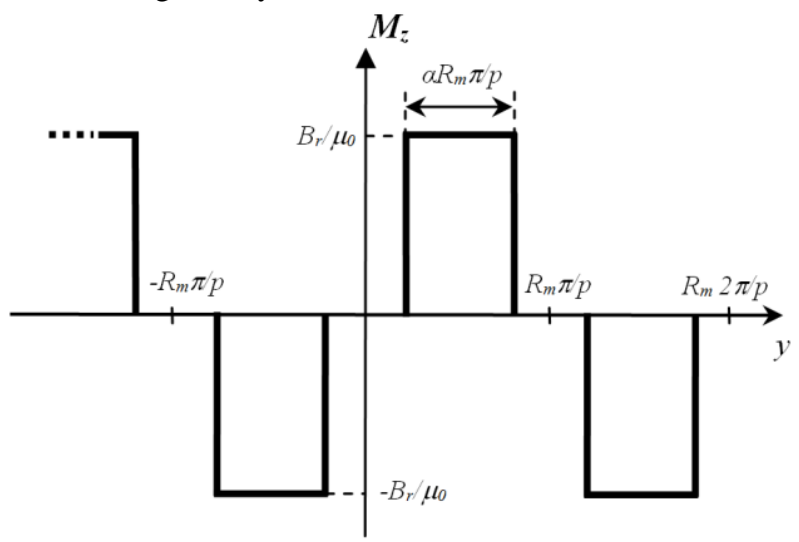

Fig. 4. Magnetization distribution along $y$-direction (region I)

$$
\begin{aligned}
K_{T}=\frac{8}{\pi} \sigma & B_{r}^{2} R_{m}^{3} L d \sin ^{2}\left(\alpha \frac{\pi}{2}\right) \\
& \times \frac{\sinh ^{2}(\beta b)}{\sinh ^{2}(\beta(b+c+d))}\left(1+\frac{\sinh (2 \beta d)}{2 \beta d}\right)
\end{aligned}
$$

As expected for low slip values, the torque is proportional to the slip speed $\Omega(r d / s)$. The expression has been arranged in order to isolate its dimensional part.

It has been shown in [18], [20] and [22] that the 3D endeffects cannot be neglected for such devices. Fig. 5 shows the actual paths of the induced currents in the conducting plate (3D effects). The induced currents flow along a closed path and not only in the $x$-direction as it was obtained with the 2D model (6). To take into account the end-effects, an efficient correction factor (10) has been given by Russel and Norsworthy [31]

$$
k_{\text {Russel }}=1-\frac{(2 / \beta L) \tanh (\beta L / 2)}{1+\tanh (\beta L / 2) \tanh (\lambda \beta L / 2)}
$$

The torque expression with the 3D effects can be finally expressed as

$$
T=K_{T}^{\prime} \Omega \quad \text { with } \quad K_{T}^{\prime}=k_{\text {Russel }} K_{T}
$$

where $K_{T}^{\prime}$ is the torque coefficient. Fig. 6 shows the variation of $K_{T}^{\prime}$ versus the air-gap length (the other parameters are those given in table I). As expected, $K_{T}^{\prime}$ decreases with the air-gap length.

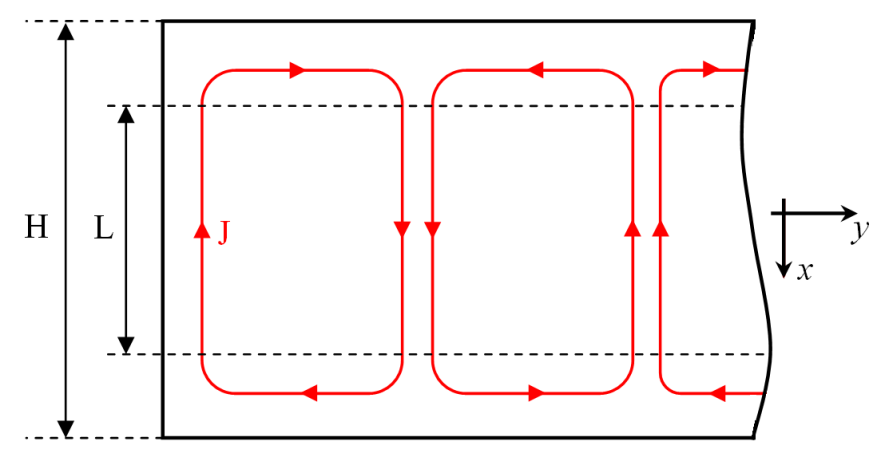

Fig. 5. Actual paths for the induced-currents (3D effects)

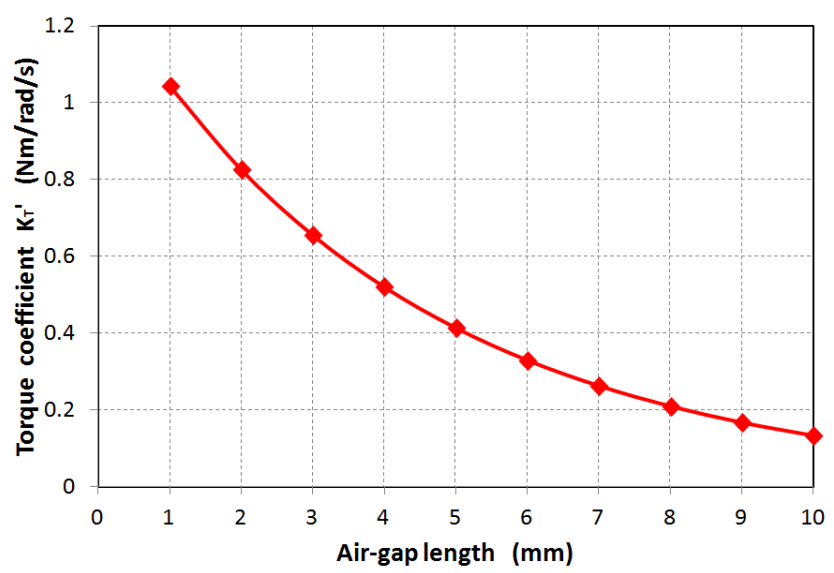

Fig. 6. Torque coefficient $\mathrm{K}_{\mathrm{T}}$ ' (Nm.s/rad) versus air-gap length for the studied magnetic coupling (Table I). 


\section{STEADY-STATE ANALYSIS}

In this section, we use the torque formula (11) to study the steady-state performances of the coupling (constant speed operation). In order to show the effectiveness of the proposed model, the results obtained with the analytical formula (11) are compared with those obtained from 3D nonlinear finite element analysis (FEA). The finite element simulations (COMSOL Multiphysics ${ }^{\circledR}$ ) are conducted by considering the reaction field due to the induced currents and the real geometry of the coupling (i.e. cylindrical structure as shown in Fig. 1). Moreover, the nonlinear magnetic property for the back-irons (B-H curve) has been considered in the finite-element simulations and is shown in Fig. 7.

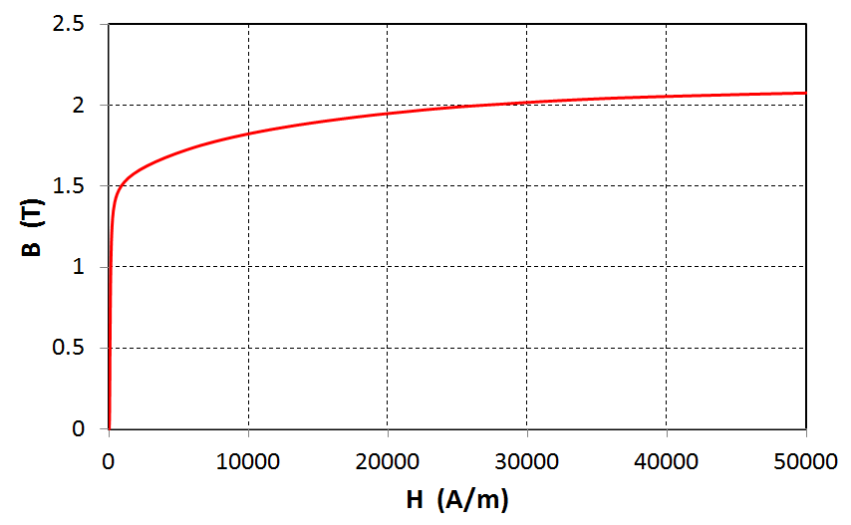

Fig. 7. $B(H)$ curve of the back-irons ( $\mathrm{M}-27$ steel) used in 3D FEA

\section{A. Torque-Speed Characteristic}

The torque-speed characteristic of the studied coupling is shown in Fig. 8. As indicated previously, only the low slip values are considered here (high efficiency area). The geometrical parameters are the ones given in Table I with $c=3 \mathrm{~mm}$. Fig. 8 shows that the torque is well predicted by the analytical formula if we consider the Russel correction factor. In this case, the deviations between the proposed formula and the 3D nonlinear FEA is always below $10 \%$.

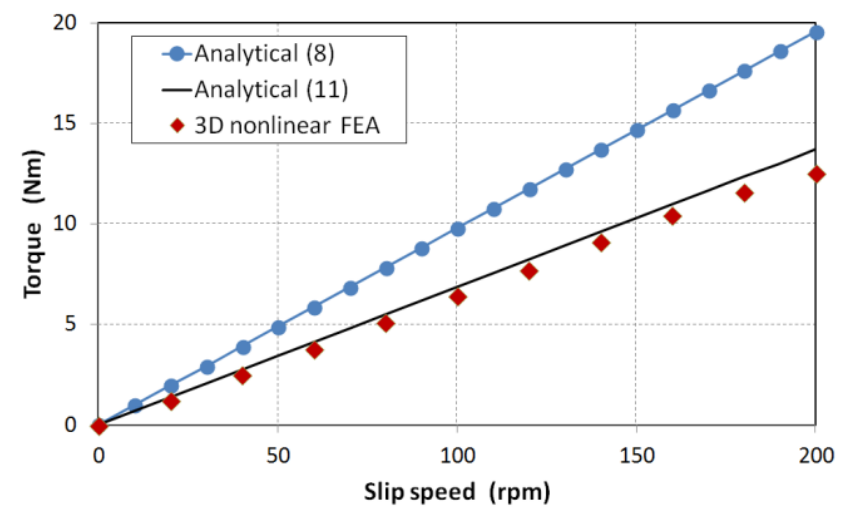

Fig. 8. Torque-speed characteristic for the studied coupling (with $\mathrm{c}=3 \mathrm{~mm}$ ): comparison between analytical results and 3D FEA.

The flux density (z-component) and the eddy-current distributions at the surface of the copper obtained with 3D FEA are respectively shown in Fig. 9a and Fig. 9b. These results correspond to a slip speed of $150 \mathrm{rpm}$. The maximum value of the flux density on the surface of the copper is around $0.55 \mathrm{~T}$ (with alternate polarity).

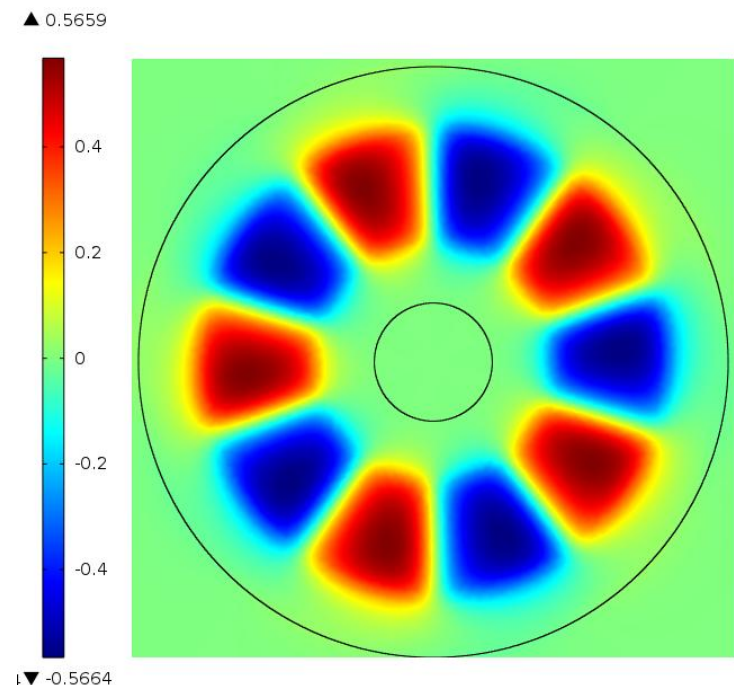

(a)

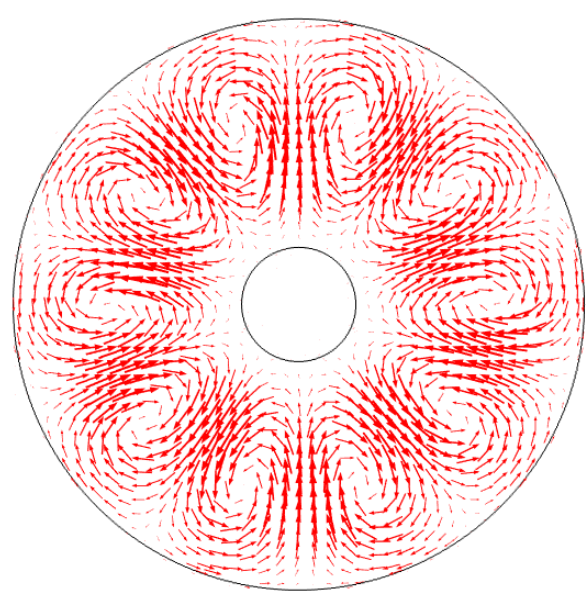

(b)

Fig. 9. 3D FEM analysis: (a) flux density distribution (z-component) on the surface of the copper, (b) eddy-current distribution at $150 \mathrm{rpm}$

\section{B. Influence of Geometrical Parameters}

The torque formula is now used to study the influence of several geometrical parameters (copper thickness, polepairs number, and the radial length of the copper). Fig. 10 shows the torque versus copper thickness. We have fixed the air-gap length $c=3 \mathrm{~mm}$ and the slip speed at $150 \mathrm{rpm}$ (the other parameters are those given in Table I). We can observe that an optimal value exists for the copper thickness ( $T \approx 10 \mathrm{Nm}$ for $d \approx 5 \mathrm{~mm}$ ). This optimal value is well predicted by the analytical formula (11) when compared to 3D FEA.

The torque versus the pole-pairs number is shown in Fig. 11. For the analysis, we have considered $c=3 \mathrm{~mm}$, the other geometrical parameters are kept constant and are given in Table I. Once again, we can observe that an optimum value exists for the pole-pairs number $(p \simeq 4)$. This optimum value is well predicted by using the torque formula. The error is never greater than $15 \%$ compared to 3D FEA.

As indicated in the nomenclature, $\lambda$ is the ratio of the radial copper end-lengths to the radial magnet length (active length): $\lambda=0$ corresponds to the same radial dimensions for the copper and the magnets $(H=L)$ whereas $\lambda=1$ corresponds to $H=2 L$. Fig. 12 shows the torque versus the ratio $\lambda$ obtained with the analytical formula and with $3 \mathrm{D}$ FEA. We can observe that the torque increases with the copper end-lengths and then becomes constant for $\lambda \geq 1$ (an 
improvement of about $75 \%$ is obtained with $\lambda=1$ compared to $\lambda=0$ ). For the studied coupling (Table I), we have therefore chosen $\lambda=1$, that corresponds to $30 \mathrm{~mm}$ additional length for the copper compared to the active length of the magnets (15 $\mathrm{mm}$ on each side as indicated in Table I). Fig. 12 clearly shows the ability of the torque formula to take into account the ratio $\lambda$. The error between analytical model and 3D FEA is not greater than $17 \%$ (for $\lambda=0$ ), and we can observe that the trend is good.

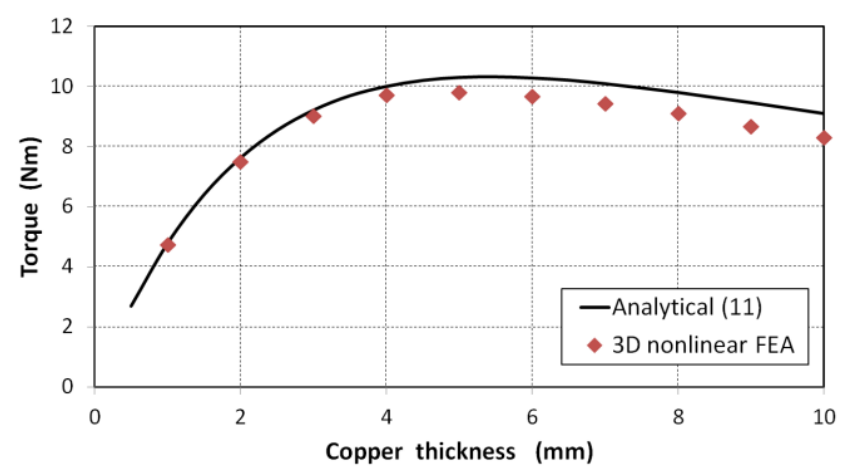

Fig. 10. Torque versus copper thickness at $150 \mathrm{rpm}$ for $c=3 \mathrm{~mm}$ and $p=5$.

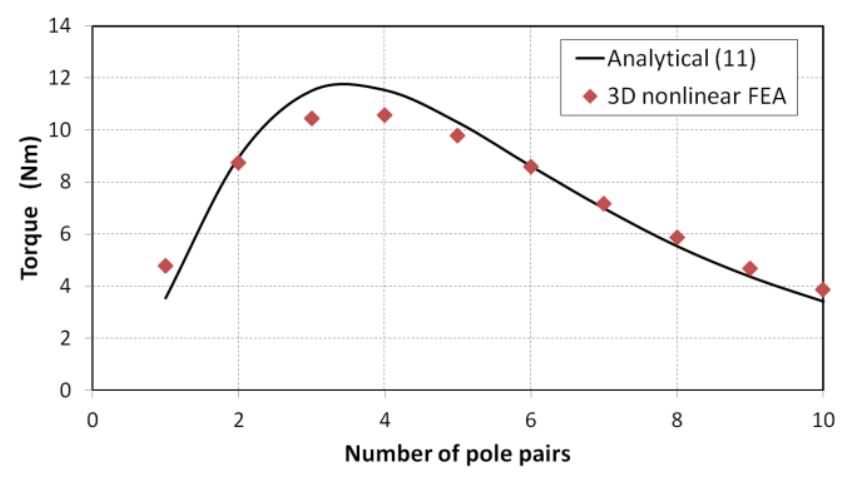

Fig. 11. Torque versus number of pole pairs at $150 \mathrm{rpm}$ for $c=3 \mathrm{~mm}$.

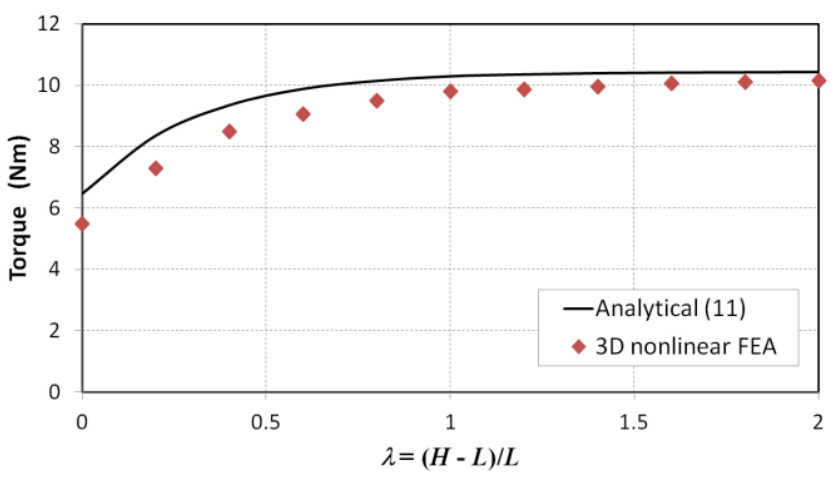

Fig. 12. Torque versus copper end-length at $150 \mathrm{rpm}$ for $c=3 \mathrm{~mm}$.

\section{Axial Force Expression}

The main drawback of axial-field couplers is the large axial force between the two discs [4]. This force must be known because it affects the bearing losses of the drive. For eddy-current couplings, the attraction force is maximal when the reaction field is null (i.e. slip speed equal to zero). The proposed analytical model can then be used to derive a closed-form expression for the axial force. By using the Maxwell stress tensor, the axial force expression is

$$
F=\frac{4}{\pi \mu_{0}} B_{r}^{2}\left(R_{2}^{2}-R_{1}^{2}\right) \sin ^{2}\left(\alpha \frac{\pi}{2}\right) \frac{\sinh ^{2}(\beta b)}{\sinh ^{2}(\beta(b+c+d))}
$$

By using (12), we obtain $F=581 \mathrm{~N}$ with the geometrical parameters given in Table I and considering $c=3 \mathrm{~mm}$. The 3D FEA gives $F=515 \mathrm{~N}$, which corresponds to an error of about $13 \%$ on the axial force prediction.

\section{Experimental validation}

For the experimental validation, we have manufactured an axial-field eddy-current coupling prototype as shown in Fig. 2. The geometrical parameters of the prototype are given in Table I. The magnetic coupling is inserted between a DC motor and a load as shown in Fig. 14 (DC motor of $3 \mathrm{~kW}, 3000 \mathrm{rpm}$ ). For the test, one shaft is locked (copper side i.e. $\Omega_{2}=0$ in Fig. 14), and the other shaft can rotate (magnets side). The speed is controlled by changing the voltage applied to the armature of the DC motor. The slip speed is measured with an encoder as shown in Fig. 14. The torque is obtained by the armature current measurement (the torque constant of the DC motor is $1,35 \mathrm{Nm} / \mathrm{A}$ ).

Fig. 13 shows a comparison between the analytically predicted torque-slip speed characteristics and the measured data. As shown in Fig. 13, three values for the air-gap length were considered ( $c=3 \mathrm{~mm}, c=5 \mathrm{~mm}$, and $c=7 \mathrm{~mm})$. It can be noticed that the experimental measurements are in good agreement with the one obtained with the proposed torque formula. The deviations between the analytical formula and the test results are not greater than $10 \%$.

However, we can observe in Fig. 13 that the error between the analytical predictions and tests becomes larger when the speed increases. This difference is due to the wellknown reaction field which can no longer be overlooked for a speed greater than $200 \mathrm{rpm}$ (for the studied coupling). In order to predict accurately the torque-speed characteristic for larger slip values, a more complex model which takes into account the reaction field effect must be used [16]-[18], but this is out of the scope of the present paper.

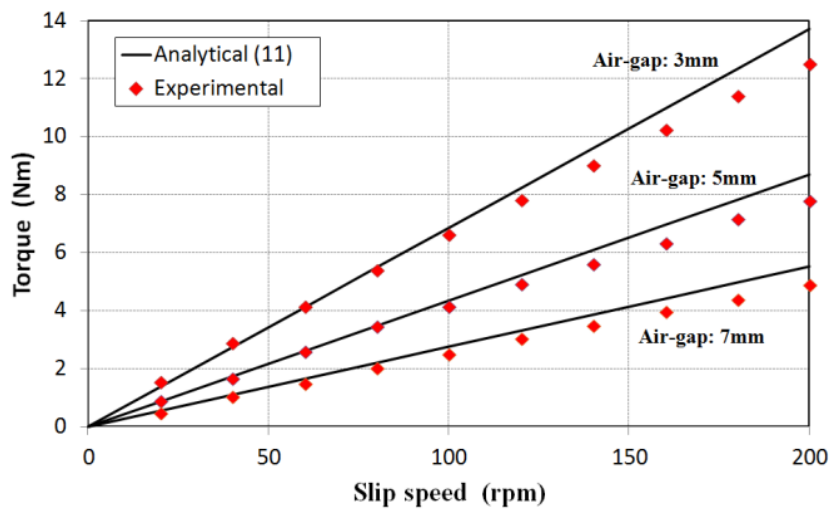

Fig. 13. Measured torque-slip speed characteristics for three values of the air-gap length ( $c=3 \mathrm{~mm}, c=5 \mathrm{~mm}$, and $c=7 \mathrm{~mm})$.

\section{TRANSIENT ANALYSIS}

The transient analysis of the magnetic coupling is obtained from the equation of motion for rotating rigid bodies. Fig. 14 shows the scheme of the test bench. The magnetic coupling is placed between two DC motors. One motor is used as the prime mover (attached to the magnets side of the coupling) and the other DC motor is used to apply a load torque (DC generator). The prime mover rotates at $\Omega_{1}$ and the load runs at $\Omega_{2}$. In steady state condition, the difference between the two speeds is a function of the load torque. Two encoders (4096 
pulses/revolution) have been placed on the test bench to measure the speed on both sides of the coupling during the transient. From Fig. 14, the motion equations are given by

$$
\begin{aligned}
& J_{1} \frac{d \Omega_{1}}{d t}+B_{1} \Omega_{1}=T_{D C}-T \\
& J_{2} \frac{d \Omega_{2}}{d t}+B_{2} \Omega_{2}=T-T_{\text {load }}
\end{aligned}
$$

where $J_{l}$ and $B_{l}$ denote the moment of inertia and the viscous damping coefficient of the DC motor, $J_{2}$ and $B_{2}$ denote the moment of inertia and the viscous damping coefficient of the load. $T_{D C}$ is the DC motor torque and $T_{\text {load }}$ is the external load torque.

Here, we consider only small variations of the slip speed. As shown in [25]-[27], eddy-current couplings can be modeled as a first order transfer function (small signal model), where $K_{T}{ }_{T}$ is the DC gain and $\tau_{c}$ is the time constant ( $s$ is the Laplace domain variable)

$$
\frac{T(s)}{\Omega(s)}=\frac{K_{T}^{\prime}}{1+\tau_{c} s} \quad \text { with } \quad \tau_{c}=\frac{1}{p \Omega_{T M A X}}
$$

$\Omega_{\text {TMAX }}$ is the slip speed ( $\left.\mathrm{rad} / \mathrm{s}\right)$ corresponding to the maximum torque of the torque to speed characteristic $\left(\Omega_{\text {TMAX }}\right.$ can be obtained by using a model which take into account the reaction field [17]). For the studied coupler (Table I), we obtain $\Omega_{T M A X}=84 \mathrm{rad} / \mathrm{s}$ which gives $\tau_{c}=$ $2.3 \mathrm{~ms}$. This time constant should be compared to the one given in (17) which takes into account the mechanical part of the system $(\tau=38.5 \mathrm{~ms}$ for $c=3 \mathrm{~mm})$. For the studied coupler, the ratio $\tau / \tau_{c} \simeq 16.7$. Therefore, $\tau$ is the dominant time constant of the system and $\tau_{c}$ can be neglected in the transient analysis. In the next developments, we assume that the torque transmitted by the magnetic coupling is proportional to the slip speed (the coupler is seen as a purely viscous torque). By considering (11), the equation of motion (13) can be re-written as

$$
\begin{aligned}
& J_{1} \frac{d \Omega_{1}}{d t}+\left(B_{1}+K_{T}^{\prime}\right) \Omega_{1}=T_{D C}+K_{T}^{\prime} \Omega_{2} \\
& J_{2} \frac{d \Omega_{2}}{d t}+\left(B_{2}+K_{T}^{\prime}\right) \Omega_{2}=K_{T}^{\prime} \Omega_{1}-T_{\text {load }}
\end{aligned}
$$

In the following sub-sections, we study three types of transient response. The first test concerns the speed response to a step input on the torque of the DC motor when the copper face of the coupling is locked (brake operation). In the second test, we study the transient performance during start-up (under no-load condition) for different values of the air-gap length. The last test concerns the speed responses on both sides of the coupling when an abrupt load variation is applied.

\section{A. $\quad$ Speed Response to a Step Input on $T_{D C}$}

In order to study the transient behavior of the coupling, a first test consists to block one part of the magnetic coupling (the load part is locked i.e. $\Omega_{2}=0$ in Fig. 14), and to apply a step input on $T_{D C}$. In this case, the motion equation (15) can be simplified to

$$
J_{1} \frac{d \Omega_{1}}{d t}+\left(B_{1}+K_{T}^{\prime}\right) \Omega_{1}=T_{D C}
$$

For this test, the eddy-current coupling acts as a brake and is equivalent to a supplementary viscous damping coefficient which is equal to the torque coefficient $K_{T}{ }_{T}$ given by (11). As indicated in (9) and (10), the torque coefficient depends directly on the coupling geometrical parameters and more particularly on the air-gap value (Fig. $6)$. For an air-gap $c=3 \mathrm{~mm}$, we obtain $K^{\prime}{ }_{T}=0.65 \mathrm{Nm} . \mathrm{s} / \mathrm{rad}$ as shown in Fig. 6.

Equation (16) is a well-known first order linear differential equation. The speed response to a step input on $T_{D C}$ is given by (17). We can define the time constant $(\tau)$ of the system and the final speed value $\left(\Omega_{l_{\infty}}\right)$. As the viscous damping coefficient of the DC motor $B_{l}$ is much lower than $K^{\prime}{ }_{T}$, it can be neglected $\left(B_{1}=0.002 \mathrm{Nm}\right.$.s $/ \mathrm{rad}$ whereas $K^{\prime}{ }_{T}$ is greater than $0.1 \mathrm{Nm} . \mathrm{s} / \mathrm{rad}$ as shown in Fig. 6). The viscous damping coefficient $B_{1}$ has been measured by the no-load test. The moment of inertia $J_{l}$ in (17) is equal to $0.025 \mathrm{~kg} . \mathrm{m}^{2}$ and has been measured by the classical freewheeling operations.

$\Omega_{1}(t)=\Omega_{1 \infty}\left(1-e^{-\frac{t}{\tau}}\right)$ with $\tau=\frac{J_{1}}{K_{T}^{\prime}}$ and $\Omega_{1 \infty}=\frac{T_{D C}}{K_{T}^{\prime}}$

Figs. 15 show the speed responses $\Omega_{l}$ (simulations and tests) when we apply a step in load torque $T_{D C}=5 \mathrm{Nm}$ at $t=$ 0s. The electromagnetic torque of the DC motor is controlled by the armature current regulation (closed loop control). As shown in Fig. 15(a), a step input $T_{D C}=5 \mathrm{Nm}$ corresponds to a step input on the DC armature current of 3.7A (torque constant of $1.35 \mathrm{Nm} / \mathrm{A}$ ).

Three values of the air-gap length are considered for this test $(3 \mathrm{~mm}, 5 \mathrm{~mm}$ and $7 \mathrm{~mm})$. Fig. 15(b) shows that the transient behavior is well predicted by the analytical model compared to the experimental results. Table II compares the time constant $\tau$ and the final speed value $\Omega_{1 \infty}$ for simulation and test. In all cases, the error is less than $9 \%$. As expected, the final speed values given in Table II correspond to the ones obtained during the steady-state analysis (Fig. 13) for a torque of $5 \mathrm{Nm}$.

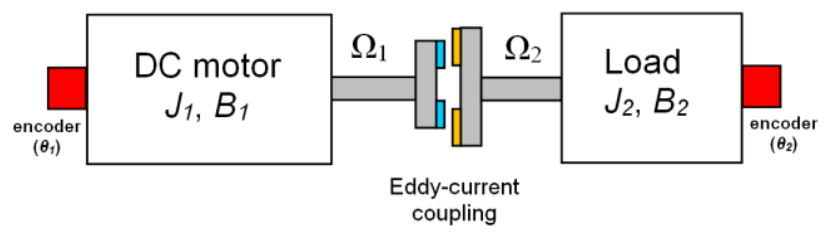

Fig. 14. Scheme of the test bench for the transient analysis

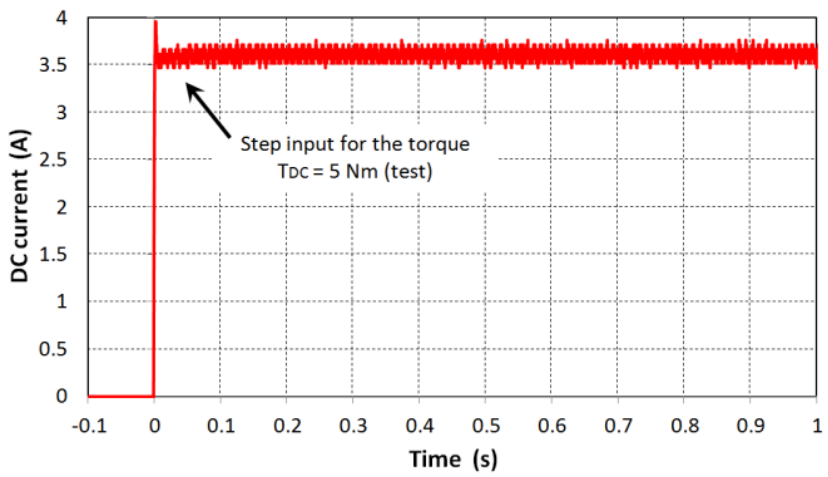

(a) 


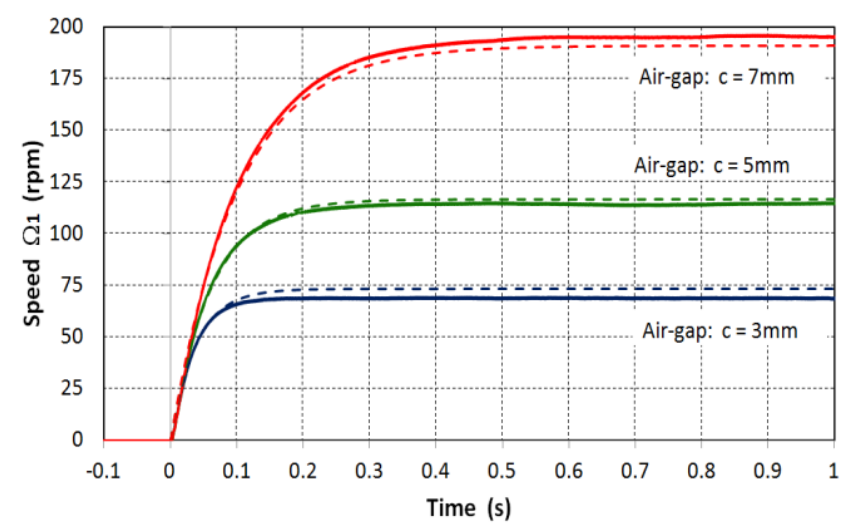

(b)

Fig. 15. Speed responses to a torque step input: (a) Step input for the torque, (b) simulation (dotted line) and experimental results (solid line).

TABLE II

COMPARISON BETWEEN TEST AND SIMULATION (TIME CONSTANT AND FINAL SPEED VALUE)

\begin{tabular}{|l|l|c|c|c|}
\cline { 2 - 5 } \multicolumn{1}{c|}{} & $\begin{array}{c}\text { Air-gap } \\
\boldsymbol{c = 3 m m}\end{array}$ & $\begin{array}{c}\text { Air-gap } \\
\boldsymbol{c = 5 m m}\end{array}$ & $\begin{array}{c}\text { Air-gap } \\
\boldsymbol{c}=\mathbf{7 m m}\end{array}$ \\
\hline \multirow{2}{*}{$\begin{array}{c}\boldsymbol{K}^{\prime}{ }_{T} \mathbf{( 1 1 )} \\
\text { Nm.s/rad }\end{array}$} & 0.65 & 0.41 & 0.26 \\
\hline \multirow{2}{*}{$\begin{array}{c}\tau \\
(\mathbf{m s})\end{array}$} & Analytical & 38 & 61 & 96 \\
\cline { 2 - 5 } & Test & 35 & 57 & 99 \\
\hline $\begin{array}{c}\Omega_{1 \infty} \\
(\mathbf{r p m})\end{array}$ & Analytical & 73 & 116 & 184 \\
\cline { 2 - 5 } & Test & 69 & 114 & 195 \\
\hline
\end{tabular}

\section{B. Transient Performance During Start-Up}

For this test, the two sides of the coupling can rotate. The principle is to start the DC motor by connecting its armature circuit to a DC source of low voltage. The DC motor starts from standstill to $400 \mathrm{rpm}$ in steady-state condition. The test is done under no-load condition $\left(T_{\text {load }}=0\right.$ in (15)).

Figs. 16-17 compare the speed response obtained with the analytical model and with experimental measurements for two values of the air-gap length $(c=3 \mathrm{~mm}$, and $c=$ $7 \mathrm{~mm}$ ). The simulation results have been obtained by using (15). We can observe in Fig. 16 and Fig. 17 that a delay time exists for the speed between the two rotors of the magnetic coupling. This delay time increases when the airgap length increases. This is due to the decrease of the torque coefficient $K_{T}^{\prime}$ with the air-gap length, as shown in Fig. 6. This delay time has to be taken into account for servomechanism application. Because of the no-load condition, the speed value in steady state is almost identical on both sides of the coupling (a little speed difference can be observed in Fig. 17 for a large air-gap i.e. $7 \mathrm{~mm}$ ).

It is worth noting that no oscillation appears on the speed responses during the transient, as it was for synchronous coupling with permanent magnets on both sides [12]. An advantage of eddy-current couplings compared to synchronous couplings is that it is free from torque ripple as shown in [29], and can be used as vibration isolation system.

Fig. 18 shows the torque transmitted by the coupler during the transient corresponding to the speed variation given in Fig. 17. We can observe that the torque reaches a maximal value of around $2 \mathrm{Nm}$ (this point corresponds to the maximum slip speed during the transient) and then is almost equal to zero in steady-state (no-load condition).

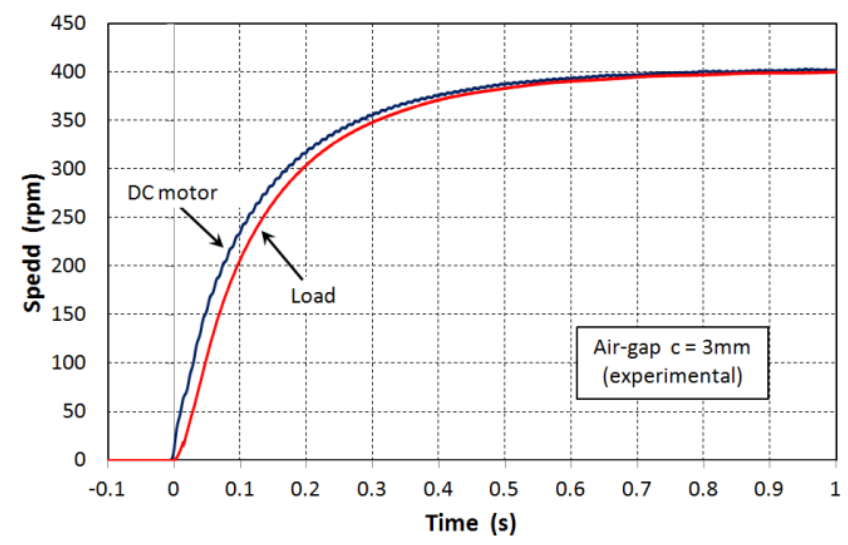

(a)

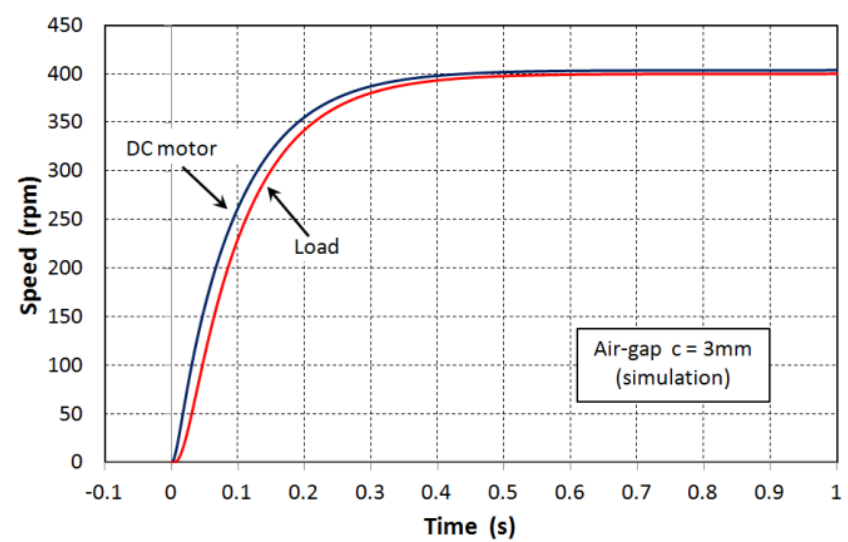

(b)

Fig. 16. Speed response during start-up for $c=3 \mathrm{~mm}$ : (a) experimental result, (b) simulation result.

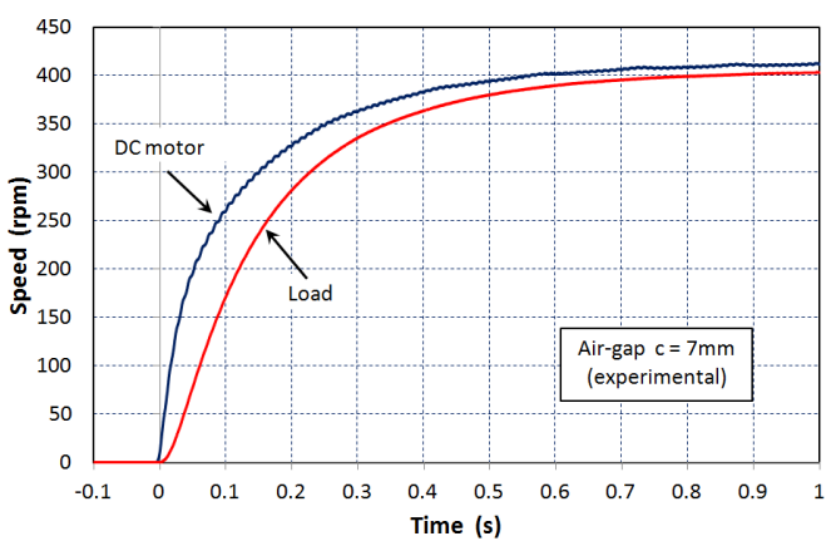

(a)

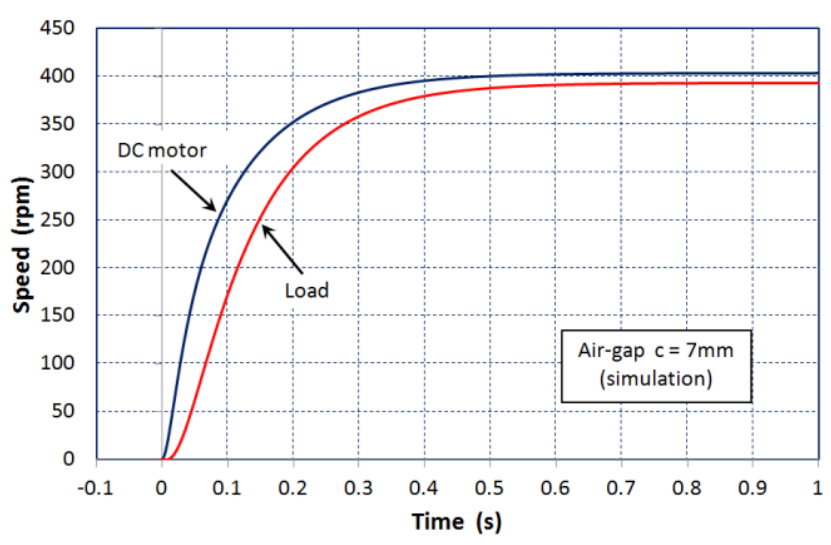

(b)

Fig. 17. Speed response during start-up for $c=7 \mathrm{~mm}$ : (a) experimental result, (b) simulation result, (c) torque simulation result. 


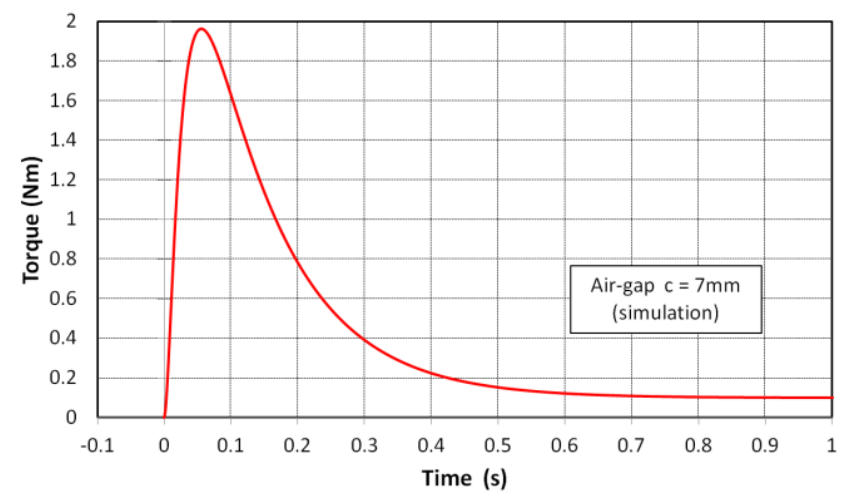

(c)

Fig. 18. Torque transmitted by the coupler during the transient.

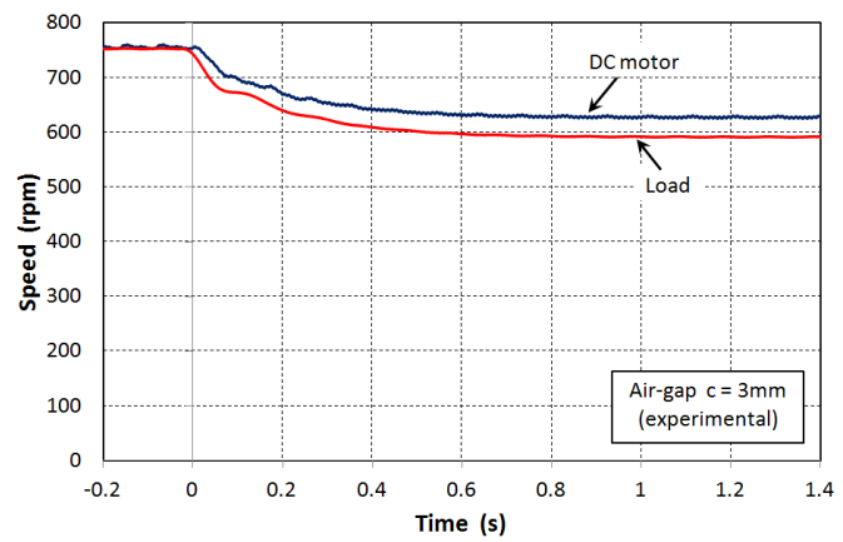

(a)

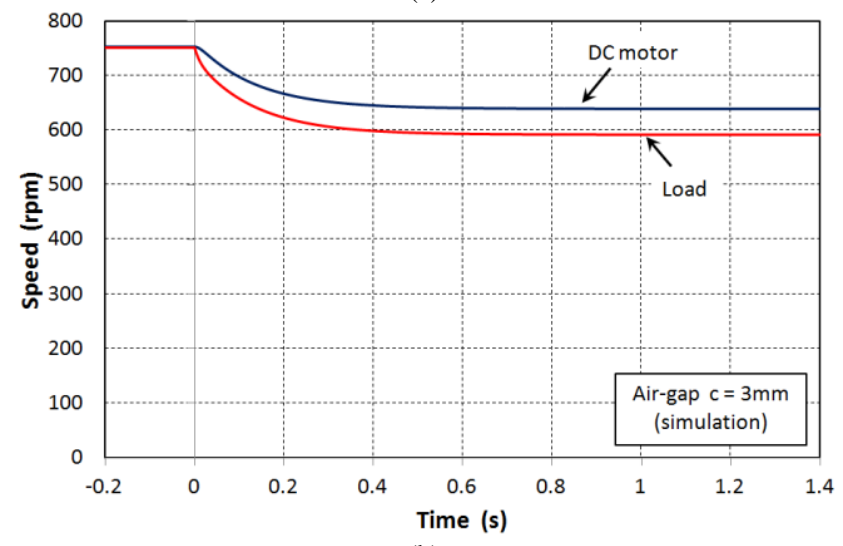

(b)

Fig. 19. Speed response to a sudden load torque of $3.2 \mathrm{Nm}$ for $c=3 \mathrm{~mm}$ : (a) experimental result, (b) simulation result.

\section{Transient Performance with Load variation}

The transient performance of the eddy-current coupling for a sudden application of load torque is now studied. Before the load torque is applied, the DC motor is in steady-state condition and runs with a speed of $750 \mathrm{rpm}$ under no-load condition. For the abrupt application of the load torque, we use a DC generator by connecting a resistance to its terminal armature winding (the mechanical parameters of the DC generator are $B_{2}=0.0015 \mathrm{Nm} . \mathrm{s} / \mathrm{rad}$ and $J_{2}=0.01 \mathrm{~kg} \cdot \mathrm{m}^{2}$ ). Once again, two values of the air-gap length are considered for this test. Figs. 19-20 show the speed responses (simulation and experimental results) for a sudden load torque of $3.2 \mathrm{Nm}$. After a transient of around $0.4 \mathrm{~s}$, the two rotors are once again in steady state but with a slip speed which depends on the air-gap value. As expected, the relative speed between the two rotors increases with the air-gap value.
Overall, we can observe closed agreements between the analytical and experimental results, which confirm the validity of the proposed model. However, it is important to keep in mind that the torque formula is only valid for low slip values and the proposed model can only predict the transient performance for small variations of the slip speed and under certain conditions indicated previously.

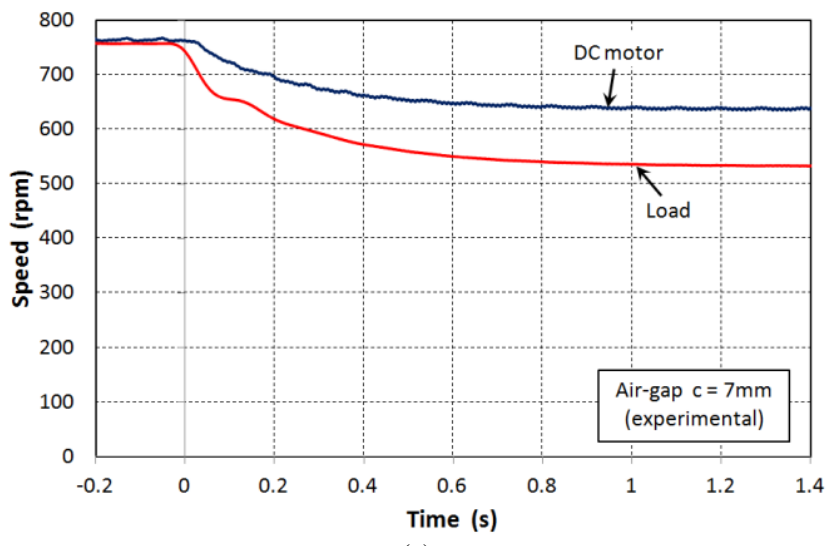

(a)

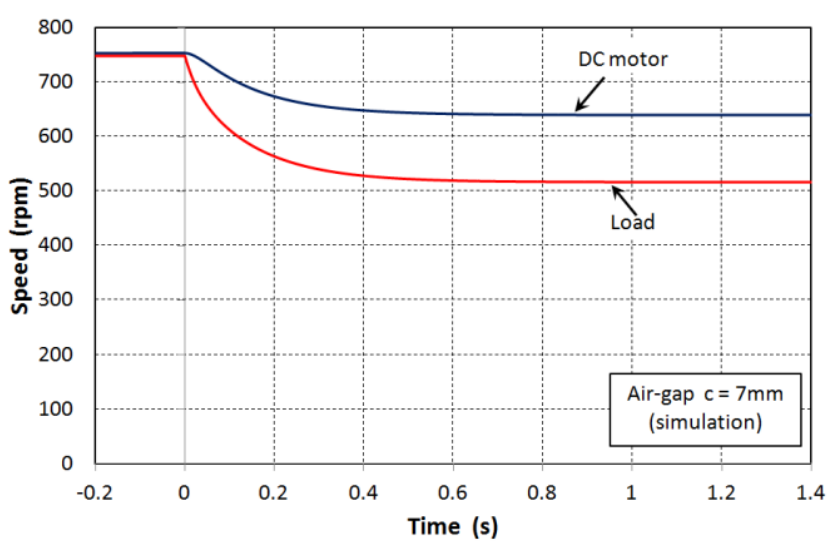

(b)

Fig. 20. Speed response to a sudden load torque of $3.2 \mathrm{Nm}$ for $c=7 \mathrm{~mm}$ : (a) experimental result, (b) simulation result.

\section{CONCLUSION}

In this paper, we have developed a simple torque formula that can be easily used for a first evaluation of eddy-current couplings performances, for both steady-state and transient operations. The proposed model is valid for low slip values but it corresponds to the normal working area of eddy-current couplings (limited temperature and high efficiency). Comparisons with 3-D finite-element simulations have shown that the torque formula is able to predict the influence of the geometrical parameters with a good precision. Therefore, it can be used as an efficient tool in the design process of eddy-current couplings.

A prototype has been built and the comparison between analytical results and tests has shown the precision of the model. An error of less than $10 \%$ has been obtained on the torque-speed characteristic. Through detailed transient analysis, we have shown that the magnetic coupling causes time delays between the two rotors during start-up. This time delay depends on the air-gap value and must be taken into account for servomechanism applications and every transient behavior. 


\section{REFERENCES}

[1] R. M. Hornreich and S. Shtrikman, "Optimal design of synchronous torque couplers," IEEE Trans. Magn., vol. 14, no. 5, pp. 800-802, Sept. 1978.

[2] E. P. Furlani, "Formulas for the force and torque of axial couplings," IEEE Trans. Magn., vol. 29, no. 5, pp. 2295-2301, Sept. 1993.

[3] J. P. Yonnet, S. Hemmerlin, E. Rulliere, and G. Lemarquand, "Analytical calculation of permanent magnet couplings," IEEE Trans. Magn., vol. 29, no. 6, pp. 2932-2934, Nov. 1993.

[4] T. Lubin, S. Mezani, and A. Rezzoug, "Simple analytical expressions for the force and torque of axial magnetic couplings," IEEE Trans. Energy Convers., vol. 27, no. 2, pp. 536-546, Jun. 2012

[5] L. J. Wu, Z. Q. Zhu, D. A. Staton, M. Popescu, and D. Hawkins, "Comparison of analytical models of cogging torque in surfacemounted PM machines", IEEE Trans. Ind. Electron., vol. 59, no. 6, pp. 2414-2425, Jun. 2012.

[6] R. Ravaud, V. Lemarquand, and G. Lemarquand, "Analytical design of permanent magnet radial couplings," IEEE Trans. Magn., vol. 46, no. 11 , pp. $3860-3865$, Nov. 2010 .

[7] F. Weizhong, and P. C. K. Luk, "Torque ripple reduction of a directdrive permanent-magnet synchronous machine by material-efficient axial pole pairing", IEEE Trans. Ind. Electron., vol. 59, no. 6, pp. 2601-2611, Jun. 2012.

[8] J. Fontchastagner, Y Lefèvre, and F. Messine, "Some co-axial magnetic couplings designed using an analytical model and an exact global optimization code," IEEE Trans. Magn., vol. 45, no. 3, pp. 1458-1461, Mar. 2009

[9] T. Lubin, S. Mezani, and A. Rezzoug, "Development of a 2D analytical model for the electromagnetic computation of axial-field magnetic gears," IEEE Trans. Magn., vol. 49, no. 11, pp. 55075521, Nov. 2013.

[10] J. F. Charpentier and G. Lemarquand, "Optimal design of cylindrical air-gap synchronous permanent magnet couplings," IEEE Trans.Magn., vol. 35, no. 2, pp. 1037-1046, Mar. 1999.

[11] N. Niguchi, and K. Hirata, "cogging torque analysis of magnetic gear", IEEE Trans. Ind. Electron., vol. 59, no. 5, pp.2189 -2197, May 2012.

[12] T. Lubin, S. Mezani, and A. Rezzoug, "Experimental and theoretical analyses of axial magnetic coupling under steady-state and transient operation", IEEE Trans. Ind. Electron., vol. 61, no. 8, pp.4356 4365, Aug. 2014.

[13] J. Krotsch and B. Piepenbreier, "Radial forces in external rotor permanent magnet synchronous motors with non-overlapping windings," IEEE Trans. Ind. Electron., vol. 59, no. 5, pp. 22672276, May 2012.

[14] E. J. Davies, "An experimental and theoretical study of eddy-current couplings and brakes," IEEE Transactions on Power Apparatus and Systems, vol. 82, no. 67, pp. 401-419, August 1963.

[15] T. W. Nehl, B. Lequesne, V. Gangla, S. A. Gutkowski, M. J. Robinson, and T. Sebastian, "Nonlinear two-dimensional finite element modeling of permanent magnet eddy current couplings and brakes," IEEE Trans. Magn., vol.30, no.5, pp. 3000-3003, Sep. 1994.

[16] A. Canova, and B. Vusini, "Design of axial eddy-current couplers," IEEE Trans. Ind. Appl., vol. 39, no. 3, pp. 1725-1733, May/June 2003
[17] A. Canova, and B. Vusini, "Analytical modeling of rotating eddycurrent couplers", IEEE Trans. Magn., vol. 41, no. 1, pp. 24-35, Jan. 2005.

[18] J. Wang, H. Lin, S. Fang, and Y. Huang, "A general analytical model of permanent magnet eddy current couplings," IEEE Trans. Magn. vol. 50, no. 1, pp., Jan. 2014.

[19] J. Y. Choi and S. M. Jang, "Analytical magnetic torque calculations and experimental testing of radial flux permanent magnet-type eddy current brakes," J. Appl. Phys., vol.111, no.7, pp. 07E712-07E7123, Apr. 2012.

[20] S. Mohammadi, and M. Mirsalim, "Double-Sided permanent-magnet radial-flux eddy-current couplers: three-dimensional analytical modeling, static and transient study, and sensitivity analysis", IET Electr. Power Appl., 2013, vol. 7, no. 9, pp. 665-679, 2013.

[21] S. Mohammadi, M. Mirsalim, and S. Vaez-Zadeh, "Non-linear modeling of eddy-current couplers," IEEE Trans. Energy Convers. 2013 vol. 29, no. 1, pp. 224-231, Mar. 2014.

[22] Z. Mouton, and M. J. Kamper, "Modeling and Optimal Design of an Eddy Current Coupling for Slip-Synchronous Permanent Magnet Wind Generators," IEEE Trans. Ind. Electron., vol. 61, no. 7, pp. 3367-3376, Jul. 2014

[23] S. Mohammadi, M. Mirsalim, S. Vaez-Zadeh, and H. A. Taleb "Analytical modeling and analysis of axial-flux interior permanentmagnet couplers", IEEE Trans. Ind. Electron., vol. 61, no. 11, pp.5940 -5947, Nov. 2014.

[24] E. J. Davis, M. T. Wright, and R. C. Jonhson, "Transient performance of eddy-current couplings," Proc. IEE, vol. 122, no. 10 pp. 1128-1136, Oct. 1975.

[25] N. Amati, A. Tonoli, A. Canova, and M. Padovani, "Dynamic behaviour of torsional eddy-current dampers: sensitivity of the design parameters," IEEE Trans. Magn., vol. 43, no. 7, pp. 32663277, Jul. 2007.

[26] A. Tonoli, "Dynamic characteristics of eddy current dampers and couplers," J. Sound Vibr., vol. 301, no. 3-5, pp. 576-591, Apr. 2007.

[27] A. Tonoli, and N. Amati, "Dynamic modeling and experimenta validation of eddy current dampers and couplers," J. Vibr. and Acoustic., vol. 130, no. 2, pp. 1-9, Apr. 2008.

[28] P. Bouwer, J.H.J. Potgieter and M.J. Kamper, "Modelling and dynamic performance of a direct-drive direct-grid slip permanent magnet wind generator", IEEE International Electric Machines and Drives Conference (IEMDC 2011), Niagara Falls (Canada), 15-18 May, 2011, pp 137-142.

[29] J.H.J. Potgieter and M.J. Kamper, "Optimum design and technology evaluation of slip permanent magnet generators for wind energy applications", IEEE Energy Conversion Congress \& Expo (ECCE), Raleigh, North Carolina (USA), Sept. 15-20, 2012, pp 2342-2349.

[30] S. Mohammadi, and M. Mirsalim, "Design Optimization of Double Sided Permanent-Magnet Radial-Flux Eddy-Current Couplers,' Electric Power Systems Research, vol. 108, pp. 282-292, 2014

[31] R. L. Russell and K. H. Norsworthy, "Eddy currents and wall losses in screened-rotor induction motors", Proc. IEE, vol. 105, no. 20, pp. 163- 175, Apr. 1958. 